\title{
Effects of Photodynamic Therapy on Staphylococcus Aureus Viability and Staphylocoagulase Activity, an Ex-Vivo Trial
}

\author{
Arash Mohammadi Tofigh ${ }^{1 *}$ and Mersedeh Karvandi ${ }^{2}$ \\ ${ }^{1}$ Associate Professor of Surgery, Laser Application in Medical Sciences Research Center, Shahid Beheshti University of Medical \\ Sciences, Tehran, Iran
}

${ }^{2}$ Associate Professor of Cardiology, Laser Application in Medical Sciences Research Center, Shahid Beheshti University of Medical Sciences, Tehran, Iran

*Corresponding author: Arash Mohammadi Tofigh, Associate Professor of Surgery, Laser Application in Medical Sciences Research Center, Shahid Beheshti University of Medical Sciences, Tehran, Iran

\section{ARTICLE INFO}

Received: 慧 July 24, 2021

Published: 絊 August 04, 2021

Citation: Arash Mohammadi Tofigh and Mersedeh Karvandi. Effects of Photodynamic Therapy on Staphylococcus Aureus Viability and Staphylocoagulase Activity, an Ex-Vivo Trial. Biomed J Sci \& Tech Res 37(5)-2021. BJSTR. MS.ID.006060.

Keywords: Photodynamic Therapy; Staphylocoagulase; Laser; Enzyme activity; Methylene blue

\section{ABSTRACT}

Introduction: This study was designed to assess photodynamic treatment (PDT) effects on biological inhibition of Staphylococcus aureus (S. aureus). It is mainly focused on reducing the activity of Staphylocoagulase (SC), an essential product of the bacteria. The PDT effects were evaluated on the inhibition of the bacteria's enzymatic activity and total bacterial count (viability).

Methods: A $650 \mathrm{~nm}$ wavelength diode laser was used with $100 \mathrm{~mW}$ output power and 2 minutes of exposure time. We used 50,100,150, and $200 \mu \mathrm{g} / \mathrm{ml} \mathrm{MB}$ dilutions as a photosensitizer. The viability of bacteria after and before laser treatment was calculated using single plate-serial dilution spotting methods. The activity of staphylocoagulase was detected by incubating it with human plasma and assessment of crude-substrate interaction.

Results: Our findings approved that 2 minutes' irradiation of $S$. aureus with $650 \mathrm{~nm}$ diode laser alone results in rising total cell number and SC activity while photosensitizing with $150 \mu \mathrm{g} / \mathrm{ml}$ concentration of MB results in significant inhibition of SC activity, compared with other groups.

Conclusion: The optimal concentration of MB dye as a photosensitizer for maximum penetration to the intracellular bacterial structure, resulting in reactive oxygen species production inside and outside the bacterial cell's plasma membrane, is $150 \mu \mathrm{g} / \mathrm{ml}$. Using a laser wavelength of $650 \mathrm{~nm}$ along with this concentration of MB reduces the activity of SC.

Abbreviations: S. aureus: Staphylococcus aureus; PDT: Photodynamic Treatment; SC: Staphylocoagulase; MB: Methylene Blue; CFU: Colony Forming Unite; MRSA: Methicillin-Resistant Staphylococcus aureus; PCAM: Prothrombin Conformational Activation Mechanism; APDT: Antimicrobial Photodynamic Treatment; ROS: Reactive Oxygen Species; IRA: S. aureus with laser irradiation; 50PDY: S. aureus suspension in $50 \mu \mathrm{g} / \mathrm{ml} \mathrm{MB}$ and laser irradiation; 100PDY: S. aureus suspension in $100 \mu \mathrm{g} / \mathrm{ml} \mathrm{MB}$ and laser irradiation; 150 PDY: S. aureus; suspension in $150 \mu \mathrm{g} / \mathrm{ml} \mathrm{MB}$ and laser irradiation; 200PDY: S. aureus suspension in $200 \mu \mathrm{g} / \mathrm{ml} \mathrm{MB}$ and laser irradiation; CHB: Casein Hydrolysate Broth; CHM: Casein Hydrolysate Medium ; SP-SDS: Single; Plate-Sequential Dilution Spotting ; OD: Optical Density ; DW: Distilled Water ; LLLT: Low-Level Laser Treatment; PS: Photosensitizer; SOD: Superoxide Dismutase 


\section{Introduction}

Staphylococcus aureus is an important pathogen with extremely high mortality in humans [1]. It has a series of harmful factors which participate in pathogenicity, such as coagulase enzyme or Staphylocoagulase (SC) [2], which distinguished S. aureus from other Staphylococcus species [3,4]. SC supports bacterial endurance inside phagocytic cells, which is the key to the pathogenic tactic of dodging host immune system reactions [5]. Accordingly, this enzyme acts to initiate the blood's coagulation by Prothrombin Conformational Activation Mechanism (PCAM), through which $\mathrm{N}$-terminal domain interacts, adheres to C-terminal of fibrinogen, and repeats the sequences [6-9]. This activity produces an active proteolytic complex (Staphylocoagulase-prothrombin complex), enhancing fibrinogen's ability to fibrin [10]. Here comes the need for new technologies that can prevent, control, and reduce the disease process's risk. Different strategies have been used to develop antibodies to forestall $S$. aureus contaminations; however, no good outcomes have been resulted [11]. It is known that some killed-vaccines and live-attenuated vaccines against $S$. aureus protect against varying antigens, but they need more research focus [12]. It is suggested that antimicrobial photodynamic treatment (PDT) represents a modality to treat $S$. aureus infection.

The PDT has a potential mechanism that can reduce Staphylocoagulase activity at a specific dose of laser irradiation along with the administration of a photosensitizer to increase the rate of cellular apoptosis [13]. This mechanism depends on Reactive Oxygen Species' production (ROS) from cytological photochromophores of irradiated cells. The photokilling effects of MB-based PDT towards $S$. aureus have been described decades ago. The present study aims to evaluate a new aspect of the use of PDT on S. aureus. We have assessed the action of $650 \mathrm{~nm}$ diode laser alone and with different concentrations of MB as an external photosensitizer to reduce SC's activity, which may help develop an anti $S$. aureus treatment.

\section{Material and Methods}

Bacterial sample. Bacterial samples were isolated from infected patients and identified using analytical profile index (API) test methods. Stock cultures were maintained on Casein Hydrolysate slant agar pH 7.4 (HiMedia) at 4 으 $\mathrm{C}$ and were sub-cultured weekly. Isolates were divided into six groups and labeled as follows:

a) Control group: $S$. aureus without treatment,

b) IRA group: S. aureus with laser irradiation,

c) 50PDY group: S. aureus suspension in $50 \mu \mathrm{g} / \mathrm{ml} \mathrm{MB}$ and laser irradiation,

d) 100PDY group: S. aureus suspension in $100 \mu \mathrm{g} / \mathrm{ml} \mathrm{MB}$ and laser irradiation, e) 150 PDY group: $S$. aureus suspension in $150 \mu \mathrm{g} / \mathrm{ml} \mathrm{MB}$ and laser irradiation,

f) and 200PDY: S. aureus suspension in $200 \mu \mathrm{g} / \mathrm{ml} \mathrm{MB}$ and laser irradiation.

We prepared five replicas of each sample.

\section{Laser Irradiation}

In this experiment, we used a diode laser (JD-R303, HUONJE $114 \mathrm{TM} / \mathrm{China}$ ) with $650 \mathrm{~nm}$ wavelength and $100 \mathrm{~mW}$ power. Table 1 shows laser parameters that we adjusted to irradiate the samples [14-16]. We used sterile Eppendorf tubes containing 1 milliliter $(\mathrm{ml})$ of growth culture $\left(5 \times 10^{6} \mathrm{cell} / \mathrm{ml}\right)$ installed in tube rack to be directly and adjacently under diode laser exposure [17]. The laser irradiation set-up was designed vertically to ensure maximum laser distribution evenly in hole suspension volume (Figure 1). Preparation of bacteria for PDT was done by taking 1 $\mathrm{ml}$ of the bacterial suspension after 18 hours of incubation and mixing with $1 \mathrm{ml}$ of $\mathrm{MB}$ solution. After irradiation, the samples were inoculated in $10 \mathrm{ml}$ of Casein Hydrolysate Broth (CHB).

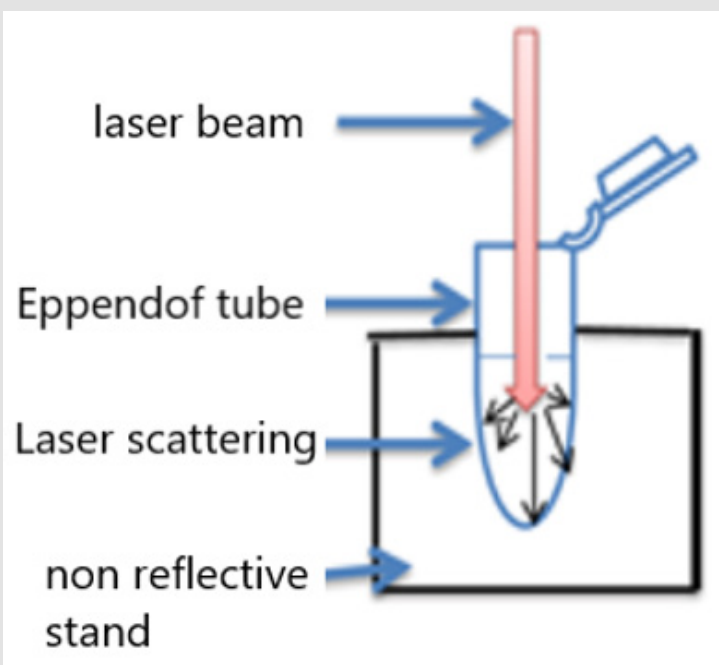

Figure 1: Laser arrangement for bacterial suspension irradiation.

Table 1: Laser irradiation parameters.

\begin{tabular}{|c|c|}
\hline Laser Parameters & Values \\
\hline Power density & 0.32 Watt $/ \mathrm{cm}^{2}$ \\
\hline Time of exposure & 2 minutes \\
\hline Type of laser proliferation & Continuous Wave \\
\hline
\end{tabular}

\section{Cultivation Methods}

S. aureus was cultivated on $20 \mathrm{ml}$ of CHB in $100 \mathrm{ml}$ Erlenmeyer flasks at 35 ㅇ for 18 hours so that the bacterial growth culture reached the exponential phase, which is optimum for enzyme production. The cultures were shaken in a shaking incubator (LSI- 
3016R / Labtech Shaking Incubator) at 190 revs. min-l [17]. The bacteria were also cultured in Casein Hydrolysate Medium (CHM) (HiMedia) at $\mathrm{PH}=7.4$, and then the number of colony-forming units per milliliter (CFU/ml) was obtained.

Staphylocoagulase Assay: According to Engels et al. we do the SC assay based on clotting time [18]. $20 \mathrm{ml}$ of culture was centrifuged (BECKMAN COULTER/Analytical Ultracentrifuge) at $12500 \mathrm{~g}$ for 2 minutes. Then $0.5 \mathrm{ml}$ of culture supernatant was blended with $0.5 \mathrm{ml}$ of human plasma and incubated at 35 으 for 4 hours. SC activity was calculated depending on clotting time. After the Staphylocoagulase-plasma reaction, the absorbance at $540 \mathrm{~nm}$ was calculated for five replicates of each sample using a UV-VIS spectrophotometer (SP-3000 nano-OPTIMA, Japan). For calculating the enzyme activity (Uml-1), the following equations were applied: [19].

$$
\Delta A=\frac{\text { Absorbance }}{\text { time of incubation }(\min u t e s)}
$$

Activity of enzyme in $\left(\mu\right.$ mol.ml $\left.{ }^{-1} \cdot \mathrm{min}^{-1}\right)$ or

$$
(u / \mathrm{ml})=\frac{\Delta A^{\circ}}{\varepsilon \times L} \times 10^{6} \times \text { volume of crudein }(\mathrm{ml})
$$

Where $\varepsilon$ : extinction coefficient of SC $=10$

$$
\text { L: optical path length }
$$

CFU Enumeration: CFU was calculated according to Thomas et al. [20]. Single Plate-Sequential Dilution Spotting (SP-SDS) technique includes preparation of CHM at pH 7.4. Each 9-cm Petridishes were divided into six sectors; each sector was labeled with the bacterial suspension's dilution factor. A stock solution of growth culture was determined by measuring the optical density (OD) at $600 \mathrm{~nm}$ utilizing a 1:10 diluted stock in a UV/VIS spectrophotometer (SP-3000 nano-OPTIMA, Japan). A serial dilution of 101-106 was set up from the 100 stocks in $1.5 \mathrm{ml}$ Eppendorf tubes with 3-5 imitates and change the tips. We used sterilized distilled water autoclaved and stored for stock and dilutions preparation. Utilizing an adjusted micropipette, $20 \mu \mathrm{l}$ of six dilutions were applied as 4-6 miniaturized scale drops in the divided sectors (sample spotting). The inoculated Petri dishes were dried off using the laminar airflow cabinet and incubated at $37^{\circ} \mathrm{C}$ for $18-24$ hours. The formula that we used to calculate $\mathrm{CFU}$ was:

$$
\text { CFU }(\text { cell } / m l)=n \times 5 \times 10^{(d+1)}
$$

where, $\mathrm{n}=$ colonies number, $\mathrm{d}=$ dilution level yielding the countable colonies.

Statistics: We analyzed our results with SPSS software version 23.0 (IBM Inc., Armonk, NY, USA). Paired sample T-test was used to analyze the enzyme activity and CFU mean values of five replicates. We made the comparisons before and after PDT with a significance level of 0.05 and control as the dependent variable. Furthermore, we used EXCEL to present our results in a column chart associated with standard error taps.

\section{Results}

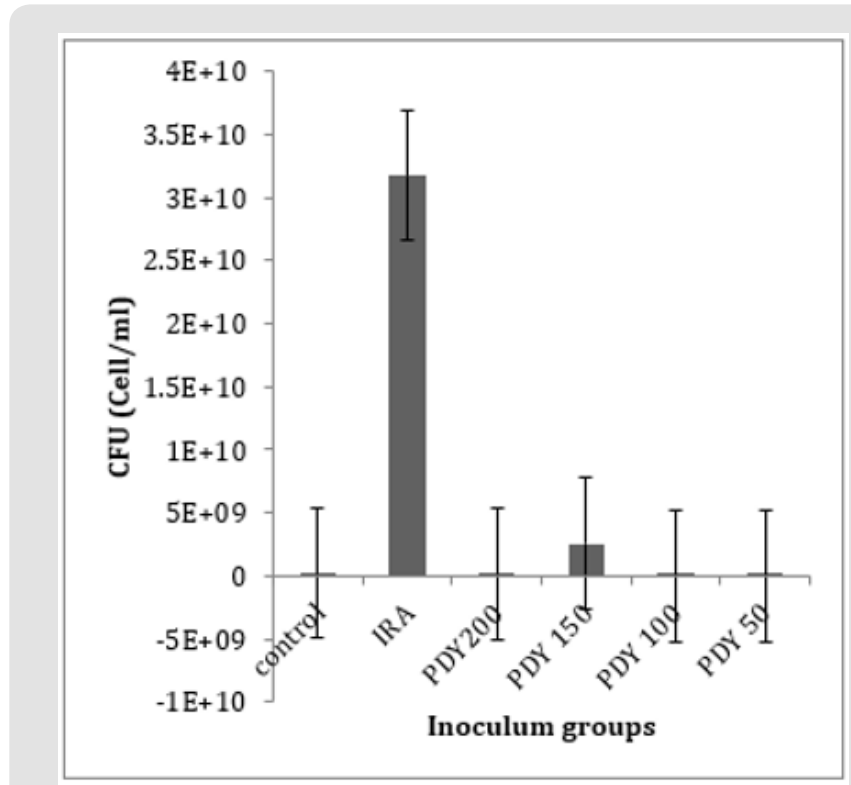

Figure 2: The mean values of CFU inoculum of control and irradiated groups.

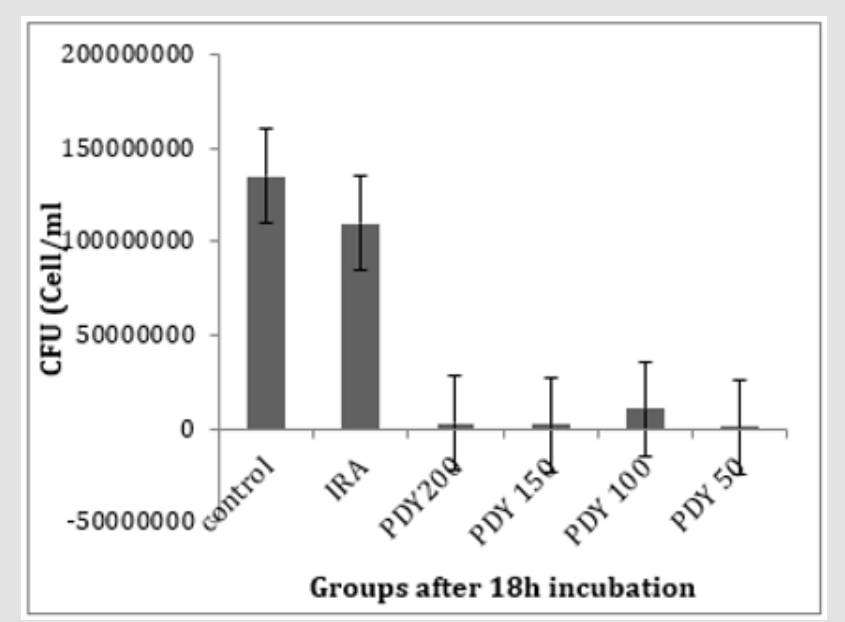

Figure 3: The mean values of CFU for control and irradiated groups, after $18 \mathrm{~h}$ incubation.

The total bacterial numbers for inoculum and exponential growth culture before and after PDT were calculated using the CFU technique described by Thomas et al. [21]. Each experiment was repeated five replicates for each sample. The mean values of inoculum in (Figure 2) show that the control, PDY200, PDY100, and PDY50 groups have the lowest values with the same mean value. In contrast, a highly increasing CFU inoculum after irradiation of the inoculum with $650 \mathrm{~nm}$ laser for 2 minutes (IRA group) was recorded. These samples were inoculated in CHB and broth 
culture immediately after irradiation. It could be noticed a slight increase in total cell number means values of the PDY150 group. After $18 \mathrm{hrs}$ of shaking incubation, each group's growth cultures were divided into two parts; the first part was serially diluted for a total bacterial count, then re-cultured and incubated for 18-24 hours at $37^{\circ} \mathrm{C}$-the dilution yielding acceptable colonies selected for CFU enumerations. The results show significant decay in CFU mean values of IRA groups compared to control groups. Simultaneously, the mean values of PDY groups produce the lowest bacterial count impact as a result of the highly bacterial dead ratio to inoculum volume after laser-photosensitizer treatment (Figure 3). Generally, there is a noticeable decrease in viable bacterial numbers after $18 \mathrm{~h}$ of the incubation period. This is mainly because of the high rate of active nutrition consumption and oxygen content during shacking incubation which shortens the exponential phase compared to the stationary growth phase. The second part of the growth culture was harvested to separate and extract crude enzyme following SC activity determination steps using a spectrophotometer at $540 \mathrm{~nm}$. The data were analyzed by comparing means using paired sample test tables and showed a significant rising and decline in SC activity at IRA and PDY150 compared to control, respectively (Figure 4). The lowest SC activity mean values were recorded in the 150PDY group.

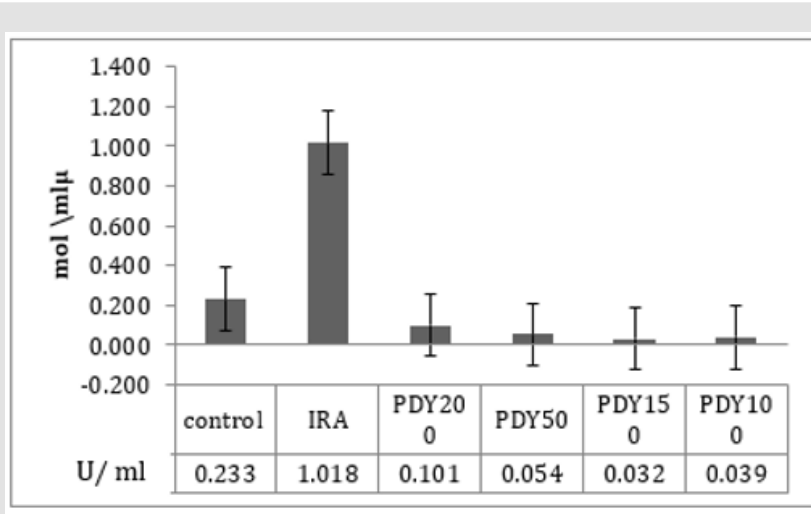

Figure 4: Mean values of SC activity as a function of nonirradiated and irradiated groups.

\section{Discussion}

The photokilling effects of MB-based PDT towards S. aureus have been described previously. The present study was designed to compare the effects of laser irradiation alone or associated with MB as a photosensitizer on $S$. aureus bacteria, mainly focused on Staphylocoagulase activity as a new aspect. We irradiated the groups of bacteria with a $650 \mathrm{~nm}$ diode laser for the same exposure time to clarify the effect of laser on bacterial growth concerning the presence or absence of methylene blue as a photosensitizer, and then we calculated the SC activity in the specimens. Our findings approved that 2 minute of irradiation of $S$. aureus with a $650 \mathrm{~nm}$ diode laser alone results in rising total cell numbers and SC activity. As noticed in (Figures 2 and 4), photo-biostimulation influence response to $650 \mathrm{~nm}$ laser on inoculum (the IRA group) after 2 minutes of laser irradiation significantly increased the SC activity $(\mathrm{P}$-value $=0.003)$. It included an increase in cell proliferation rate and biomass of bacteria after overnight culturing. These results are contradictory to the findings of Chung et al. [21]. According to Chunǵs study, where they irradiated three different bacteria species, S. aureus, E. coli, and P. aeruginosa, with nine unique laser frequencies for 15 minutes, none of the laser frequencies caused noteworthy distinction in growth on any of the three organisms' species. Our hypothesis is that exposing the micro-organisms to laser treatment for an extended period, such as Chung's study, leads to thermal effect instead of photo-biostimulation, and thermal accumulation limits actively the ionization of intracellular chromophores [22,23].

Another study by Andraus et al. has reported that low-level laser therapy (LLLT) with $660 \mathrm{~nm}$ or $808 \mathrm{~nm}$ lasers has no bactericidal effect and no hindrance growth in the illuminated region of plates at different irradiation times (2.15 $\mathrm{min}, 1.7 \mathrm{~min}$ and 40 seconds) [24]. We hypotheses that the form of prepared bacterial biofilm for irradiation represents a critical factor to observe the effect of LLLT on bacterial growth and its intracellular biomolecules activities. Chung and Andraus used to irradiate bacterial culture on the medium plate in an illuminated room that provides highly accumulated concentration of bacteria that prevented total absorption of laser wavelengths despite using different wavelengths, powers, intensities, and irradiation time. In the present experiment, we prepared liquid cell suspension to be irradiated and inoculated for subculturing. (Figure 3) shows a slight drop in CFU mean values of the IRA group after 24 hours of incubation compared to control despite a significant increase in the same group's SC activity. This occurs due to accelerating cell division rate, nutrition consumption, and shifting in the lag phase after the photo-biostimulation effect. These findings match the results of Jadah et al. [25]. PDT has adequacy against a broad spectrum of Gram-positive and Gramnegative bacteria and other types of micro-organisms. It has a multi-target mechanism [26-30], autonomously affecting their protection from standard antimicrobial treatment [31-32]. This method requires a photosensitizer (PS), light, and oxygen. The PS when energized by laser light within sight of $\mathrm{O}_{2}$, produces receptive oxygen species (ROS) like superoxide $(02 \bullet-)$, hydrogen peroxide $\left(\mathrm{H}_{2} \mathrm{O}_{2}\right)$, hydroxyl radical $(\bullet \mathrm{OH})$ created by type I systems, and singlet oxygen $\left({ }^{1} \mathrm{O}_{2}\right)$ (type II systems) [33].

The impacts of $02 \bullet-$ and $\mathrm{H}_{2} \mathrm{O}_{2}$ are less intense than those of - $\mathrm{OH}$ and ${ }^{1} \mathrm{O}_{2}$ since the latter two are substantially less responsive to detoxification by endogenous antioxidants. Examples of that antioxidants system are catalase, superoxide dismutase 
(SOD), peroxidase, regulatory genes RpoE, RpoHII, and RoHS Conversely, no enzyme can detoxify $\bullet \mathrm{OH}$ or ${ }^{1} \mathrm{O}_{2}$, making them intensely cytotoxic [34]. As indicated, we can use photodynamic conventions to reduce the virulence of $S$. aureus without affecting total cell viability. Therefore, this trial represents the PDT protocol to battle against SC without affecting the bacteria's total viable count. To provide an optimal cultivation condition and maximum production of the virulence enzyme (SC) from S. aureus, which occurs only in the exponential growth phase, we utilize CHB as the optimal production medium and suitable shacking incubation parameters (190 revs. Min- $1,35^{\circ} \mathrm{C}$ for $18 \mathrm{~h}$ ) [22]. Photosensitizing with $\mathrm{MB}$ at a $150 \mu \mathrm{g} / \mathrm{ml}$ concentration results in significant inhibition on SC activity compared with other groups. It can be hypothesized that photodynamic influence is more effective at 150 $\mu \mathrm{g} / \mathrm{ml}$ concentration of MB. It is the optimal concentration of MB for maximum penetration to the intracellular bacterial structure, resulting in ROS production inside and outside the plasma membrane of the bacterial cell [35]. This can be seen in (Figure 2) by sudden increases of CFU mean values in the PDY150 group. Another PDT consequence effect was distortion in RNA-related organelles that will be inherited to successive generations; therefore, after $18 \mathrm{~h}$ of cell proliferation, significant SC activity inhibition is seen (Figure 3 ) in the 150PDY group. It means that photodynamic treatment can cause inherited distortion in cytoplasmic organelles, which is responsible for low production of SC, or there was a shifting in the lag phase of bacterial growth, which leads to the lowest secretion of SC. For both hypotheses, we produce attenuated bacteria with low potential of SC as a virulent factor [36]. Morphological studies by Bertoloni et al. support the first. They have concluded that irradiation of eukaryotic cells with Helium-Neon laser at $632 \mathrm{~nm}$ increased packing of the cytoplasmic matrix and number of ribosomes until almost complete disappearance of the microorganisms [37].

In our study, laser arrangement for bacterial suspension irradiation was designed vertically to ensure maximum laser distribution evenly in hole suspension volume. The thermal effects of laser radiation on the specimens should also be discussed. Because if the number of viable bacteria in each sample decreases due to these thermal effects, it can affect the enzyme activity in the results [32]. Our results show an increase in the number of bacterial colonies after two minutes of laser irradiation alone (Figure 2). Therefore, the rise in temperature does not seem to have much effect on our results.

\section{Conclusion}

The most effective PDTś parameters which reduce SC activity were diode laser at $650 \mathrm{~nm}$ wavelength, $100 \mathrm{~mW}$ power, 2 minutes' irradiation time, liquid bacterial suspension to be exposed directly to laser irradiation, and MB concentration of $150 \mu \mathrm{g} / \mathrm{ml}$. These conditions cause inhibition in SC activity without affecting bacterial viability after $24 \mathrm{~h}$ of incubation. This method can potentially be an effective way to treat $S$. aureus infections, especially the methicillinresistant $S$. aureus (MRSA). However, serial studies associated with immune response and another virulence factor of $S$. aureus are still needed.

\section{Ethical Considerations}

This article does not contain any studies with human participants or animals performed by any of the authors.

\section{Conflict of Interests}

The authors declare that they have no conflict of interests.

\section{Funding}

This work was supported by the Vice- Chancellor's Office in Research Affaires, Shahid Beheshti University of Medical Sciences [grant numbers 0988/2018].

\section{References}

1. Moran GJ, Amii RN, Abrahamian FM, Talan DA (2005) Methicillinresistant Staphylococcus aureus in community-acquired skin infections. Emerg Infect Dis 11(6): 928-930.

2. Harris LG, Foster SJ, Richards RG (2002) An introduction to Staphylococcus aureus and techniques for identifying and quantifying S. aureus adhesins in relation to adhesion to biomaterials: Review. Eur Cell Mater 31: 39-60.

3. Levinson W, Jawetz E (2003) Medical Microbiology and Immunology: Examination and Board Review. 7th Edn McGraw-Hill Companies Inc, Singapore. 2003

4. Bello CS, Qahtani A (2004) Pitfalls in the routine diagnosis of Staphylococcus aureus. Afr J Biotechnol 4(1): 83-86.

5. Haraldsson I, Jonsson O (1984) Histopathology and pathogenesis of mouse mastitis induced with Staphylococcus aureus mutans. J Comp Path 94(2): 183-189.

6. Friedrich R, Panizzi P, Fuentes-Prior P, Richter K, Verhamme I, et al. (2003) Staphylocoagulase is a prototype for the mechanism of cofactorinduced zymogen activation. Nature 425(6957): 535-539.

7. Kawabata S, Morita T, Miyata T, Iwanaga S, Igarashi H, et al. (1986) Isolation and characterization of staphylocoagulase chymotryptic fragment. Localization of the procoagulant- and prothrombin-binding domain of this protein. J Biol Chem 261(3): 1427-1433.

8. Heilmann C, Herrmann M, Kehrel BE, Peters G (2002) Platelet-binding domains in 2 fibrinogen-binding proteins of Staphylococcus aureus identified by phage display. J Infect Dis 186(1): 32-39.

9. Hemker HC, Bas BM, Muller AD (1975) Activation of a proenzyme by a stoichiometric reaction with another protein. The reaction between prothrombin and staphylocoagulase. Biochim Biophys Acta 379(1): 180188

10. Panizzi P, Friedrich R, Fuentes-Prior P, Bode W, Bock PE, et al. (2004) The staphylocoagulase family of zymogen activator and adhesion proteins. Cell Mol Life Sci 61(22): 2793-2798.

11. Sandi NA, Wanahari TA, MacPhillamy I, Salasia SIO, Mappakaya BA, et al. (2015) Staphylococcus aureus Vaccine Candidate from MRSA Isolates: The Prospect of a Multivalent Vaccine. Amr J of Infec Dis 11 (3): 54-62. 
12. Pellegrino M, Giraudo J, Raspanti C, Nagel R, Odierno L, et al. (2008) Experimental trial in heifers vaccinated with Staphylococcus aureus avirulent mutant against bovine mastitis. Vet Microbiol 127(1-2): 186190.

13. Rahbar Layegh E, Fadaei Fathabadi F, Lotfiniac M, Zarea F, Mohammadi Tofigh A, et al. (2020) Photobiomodulation therapy improves the growth factor and cytokine secretory profile in human type 2 diabetic fibroblasts. Journal of Photochemistry and Photobiology B: Biology 210(1): 111962

14. Lukšienė Ž (2003) Photodynamic therapy: mechanism of action and ways to improve the efficiency of treatment. MEDICINA 39(12): 11371150 .

15. Enwemeka CS (2008) Standard parameters in laser phototherapy. Photomed Laser Surg 26(5): 411-412.

16. Enwemeka CS (2009) Intricacies of dose in laser phototherapy for tissue repair and pain relief. Photomed Laser Surg 27(3): 387-393.

17. Mahdi RA, Mohammed AA (2010) Photodynamic Inactivation of Candida Albicans Sensitized by Malachite Green. Iraqi J Laser B9(2): 31-36.

18. Engels W, Kamps M, Van Boven CPA (1978) Influence of Cultivation Conditions on the Production of Staphylocoagulase by Staphylococcus aureus 104. J of Gen Micro 109(2): 237-243.

19. Hendrix H, Lindhout T, Mertens K, Engels W, Hemker HC, et al. (1983) Activation of Human Prothrombin Stoichiometric of Staphylocoagulase. The J of Bio Chem 285(6): 3637-3644.

20. Thomas P, Sekhar AC, Upreti R, Mujawar MM, Pasha SS, et al. (2015) Optimization of single plate-serial dilution spotting (SP-SDS) with sample anchoring as an assured method for bacterial and yeast CFU enumeration and single colony isolation from diverse samples. Biotech Repo 8: 45-55.

21. Chung W, Petrofsky JS, Laymon M, Logoluso J, Park J, et al. (2014) The effects of low level laser radiation on bacterial growth. Phys Ther Rehabil Sci 3(1): 20-26.

22. Baxter D (2003) Low intensity laser therapy. In: Kitchen S, publisher. Electrotherapy: evidence-based practice. 11th ed. São Paulo Manole 171-190.

23. Christiansen C, Desimone NA (1999) Bactericidal effect of 0.95$\mathrm{mW}$ helium-neon and 5-mW indium-gallium-aluminum-phosphate laser irradiation at exposure times of 30,60, and 120 seconds on photosensitized Staphylococcus aureus and Pseudomonas aeruginosa in vitro. Physical Therapy 79(9): 839-846.

24. Andraus RAC, Maia LP, dos Santos JPM, Mesquita AR, Santos TG, (2015) Analysis of lowlevel laser therapy in vitro cultures of bacteria and fungi. MTP\& Rehab Journal 13: 304.

25. Jadah NA, Aziz GM, Anwer AG (2011) Action of Nd: YAG Laser on Growth of Saccharomyces cerevisiae. Iraqi Agric 16 (2): 231-237.

\section{ISSN: 2574-1241}

DOI: 10.26717/BJSTR.2021.37.006060

Arash Mohammadi Tofigh. Biomed J Sci \& Tech Res

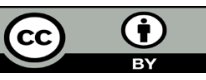

This work is licensed under Creative

Commons Attribution 4.0 License

Submission Link: https://biomedres.us/submit-manuscript.php
26. Bartolomeu M, Rocha S, Cunha Â, Neves MGPMS, Faustino MAF, et al. (2016) Effect of Photodynamic Therapy on the Virulence Factors of Staphylococcus aureus. Front Microbiol 7: 1-11.

27. Branco TM, Valério NC, Jesus VI, Dias CJ, Neves MGPMS, et al. (2018) Single and combined effects of photodynamic therapy and antibiotics to inactivate Staphylococcus aureus on skin. Photodiagn Photodyn Ther 21: 285-293.

28. Sousa V, Gomes ATP, Freitas A, Faustino MAF, Neves MGPMS, et al. (2019) Photodynamic Inactivation of Candida albicans in Blood Plasma and Whole Blood. Antibiotics 8(4): 221.

29. Almeida J, Tomé JPC, Neves MGPMS, Tomé AC, Cavaleiro JAS, et al. (2014) Almeida A. Photodynamic inactivation of multidrug-resistant bacteria in hospital wastewaters: Influence of residual antibiotics. Photochem Photobiol Sci 13(4): 626-633.

30. Gulías Ò, McKenzie G, Bayó M, Agut M, Nonell S, et al. (2020) Effective Photodynamic Inactivation of 26 Escherichia coli Strains with Different Antibiotic Susceptibility Profiles: A Planktonic and Biofilm Study. Antibiotics 9(3): 98

31. Dai T, Tegos GP, Timur Z, Eleftherios M, Hamblin MR, et al. (2010) Photodynamic Therapy for Methicillin-Resistant Staphylococcus Aureus Infection in a Mouse Skin Abrasion Model. Lasers Surg Med 42(1): 3844.

32. Tavares A, Dias SR, Carvalho CMB, Faustino MAF, Tomé JPC, et al. (2011) Mechanisms of photodynamic inactivation of a Gram-negative recombinant bioluminescent bacterium by cationic porphyrins. Photochem Photobiol Sci 10(10): 1659-1669.

33. Costa L, Faustino MAF, Tomé JPC, Neves MGPMS, Tomé AC, et al. (2013) Involvement of type I and type II mechanisms on the photoinactivation of non-enveloped DNA and RNA bacteriophages. J Photochem Photobiol;B Biol 120: 10-16.

34. Adelaide A (2020) Photodynamic Therapy in the Inactivation of Microorganisms. Antibiotics 9(4): 138.

35. Fatma V, Wanessa CMA, de M, Pinar A, Daniela V, et al. (2013) Antimicrobial strategies centered around reactive oxygen species bactericidal antibiotics, photodynamic therapy, and beyond. FEMS Microbiol Rev 37(6): 955-989.

36. Rahbar Layegh E, Fadaei Fathabadi F, Lotfinia M, Zare F, Mohammadi Tofigh A, et al. (2020) Photobiomodulation therapy improves the growth factor and cytokine secretory profile in human type 2 diabetic fibroblasts, Journal of Photochemistry and Photobiology B: Biology 210 (1): 111962.

37. Bertoloni G, Sacchetto R, Baro E, Ceccherelli F, Jori G, et al. (1993) Biochemical and morphological changes in Escherichia coli irradiated by coherent and non-coherent 632.8nm light. J Photochem Photobiol B Biol 18(2-3): 191-196.

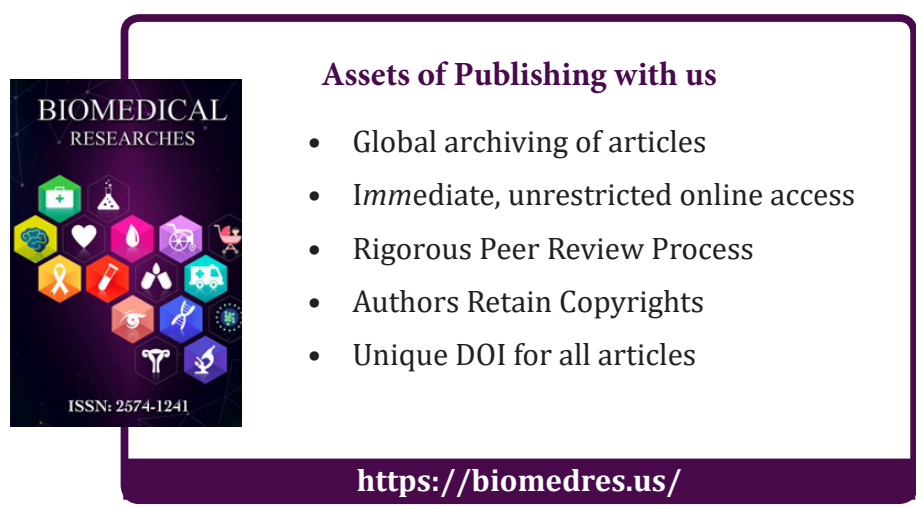

